\title{
Endocranial restoration and volume estimation of the Minatogawa IV cranium using micro-CT and 3D printer systems
}

\author{
Daisuke $\mathrm{KUBO}^{1 *}$, Reiko T. KONO ${ }^{2}$ \\ ${ }^{1}$ Department of Biological Sciences, Graduate School of Science, The University of Tokyo, Tokyo 113-0033, Japan \\ ${ }^{2}$ Department of Anthropology, National Museum of Nature and Science, Tokyo 169-0073, Japan
}

Received 28 February 2011; accepted 31 May 2011

\begin{abstract}
The Minatogawa IV cranium is one of three well-preserved Late Pleistocene Homo sapiens crania from the Minatogawa fissure site, Okinawa Island. This cranium is more damaged than Minatogawa I and exhibits some clear post-mortem distortion. We reconstructed the endocranium of this specimen after correcting the distortion and breakage by combining digital and manual restoration procedures, and established a reliable estimate for its endocranial volume (ECV) to be around $1170 \mathrm{cc}$. As with the case of Minatogawa I, this result confirmed the suggestion of previous work that the Minatogawa series has small ECVs compared with modern Japanese and Jomon populations. Some dental and osteological conditions, such as heavy tooth wear as well as Harris's lines of the long bones, suggest a possibility that the small ECV of the Minatogawa people as well as their short stature might have been caused in part by a stunting of growth due to undernutrition and possibly a microevolutionary adaptation to the food-limited insular environments.
\end{abstract}

Key words: endocranial volume, Minatogawa, Late Pleistocene, micro-CT, insular environment

\section{Introduction}

The Minatogawa IV cranium is one of three substantial crania of Homo sapiens (I, II, and IV) from the Minatogawa limestone quarry fissure site, Okinawa Island (Suzuki and Hanihara, 1982). The Minatogawa skeletal remains derived from the terminal Pleistocene (Matsu'ura and Kondo, 2011; Kaifu and Fujita, 2011), but some of them, including Minatogawa IV, may be chronologically younger than others such as Minatogawa I (Matsu'ura and Kondo, 2011). Most of the previous studies on the cranial morphology of the Minatogawa series have focused on a single, wellpreserved male cranium, Minatogawa I (e.g. Baba et al., 1998; Brown, 1999; Mizoguchi, 2011; Kubo et al., 2011), while less attention has been paid to the Minatogawa II and IV crania, which are considered to be female (Suzuki, 1982). However, morphological study on the latter is also necessary in order to clarify the group characteristics of the Minatogawa people.

Although the Minatogawa IV cranium is the second best preserved crania from the site, much of the cranial base as well as the left temporal bone are missing. In addition, the current reconstruction exhibits some obvious distortion: the right temporal bone that contacts with a fragment of the sphenoid tilts inward and shows unusual angulation at the

* Correspondence to: Daisuke Kubo, Department of Biological Sciences, Graduate School of Science, The University of Tokyo, 7-3-1 Hongo, Bunkyo-ku, Tokyo 113-0033, Japan.

E-mail: dkubo@biol.s.u-tokyo.ac.jp

Published online 13 July 2011

in J-STAGE (www.jstage.jst.go.jp) DOI: 10.1537/ase.110228 squamous suture. The basal part of the occipital bone is also slightly tilted, and its right side is dorsoventrally higher than the left side. These parts adhere to the rest of the cranial bones and each other by adhesion bonds. The endocranial volume $(\mathrm{ECV})$ of this cranium was reported by Suzuki (1982) to be $1090 \mathrm{cc}$ by the millet seed method, but this estimate may be affected by the distortion and breakage in addition to some measurement error associated with this method as discussed in Kubo et al. (2008).

The primary purpose of this study is to reconstruct the Minatogawa IV endocranium and obtain a reliable estimate of its ECV. It is difficult to correct the above-mentioned distortion and reconstruct the missing part of the cranial base with the actual specimen itself because of extensive breakage. In order to resolve this problem, microcomputed tomography (micro-CT) and three-dimensional (3D) printer systems were utilized. The reconstruction using the microCT system has the following advantages compared to that based on the actual specimen: (1) on CT imagery, removal of the sediment matrix or adhesive bond from the fossil specimen and separation and/or reconnection of parts of the cranium can be conducted in a reversible and nondestructive fashion; (2) it is easy to generate mirror images of parts of the cranium, which will compensate for the missing parts (Zollikofer et al., 2005; Kaifu et al., 2011; Suwa et al., 2009). This helps to determine approximate configurations among the separated parts of the cranium. On the other hand, the digital restoration based on $\mathrm{CT}$ imagery has a disadvantage in that it is difficult to fully perceive spatial information on a computer display because of its $2 \mathrm{D}$ nature. Use of physical replicas of the digital models (Zollikofer and Ponce de León, 2005), made by a 3D printer system, can resolve 
this disadvantage.

The second purpose of this study is to assess the characteristics of the Minatogawa series in terms of ECV from a microevolutionary perspective. For this purpose, the ECVs of Minatogawa I and IV are to be compared with those of the Jomon people, the early-middle Holocene inhabitants in the Japanese archipelago. The possible genealogical relationship between Minatogawa and Jomon people remains under debate (e.g. Kaifu et al., 2011; Saso et al., 2011). The Jomon people tended to have a large head (e.g. Ogata, 1981) and their reported ECVs (Kiyono and Miyamoto, 1926; Kintaka, 1928; Suzuki, 1982) are comparable to those of modern Japanese people (e.g. literature listed in Suzuki et al., 1956). Most of these studies probably estimated ECV by filling the endocranial cavity with granular materials such as millet seeds, but this method is not as accurate as that based on micro-CT data (Kubo et al., 2008). In this study, we measure ECVs of Jomon crania using micro-CT data to compare with the Minatogawa series.

\section{Materials and Methods}

\section{CT data acquisition}

The Minatogawa IV cranium was scanned by a TXS225ACTIS microfocal X-ray CT system (TESCO Co., Tokyo) at the University Museum, The University of Tokyo. The scanning parameters were $170 \mathrm{kV}$ tube voltage, $0.30 \mathrm{~mA}$ tube current, $0.350 \mathrm{~mm}$ slice thickness, and a reconstructed pixel size of $0.350 \mathrm{~mm}$. A copper prefilter of $1.5 \mathrm{~mm}$ was used to reduce beam-hardening artifacts. A total of 543 serial slices were taken at $0.350 \mathrm{~mm}$ intervals. The volume data of the Minatogawa IV cranium was reconstructed as a $512 \times 512 \times 543$ matrix of isotropic voxels of $0.350 \mathrm{~mm}$ size with 16-bit grayscale values.

Fifty-two modern Japanese crania (32 male and 20 female) were also scanned as a comparative sample. All crania are housed in the University Museum, The University of Tokyo. Since 43 of them had their vault horizontally cut, the separated vault was reattached before scanning accounting for loss of bone at the plane of section. The scanning parameters used for the modern Japanese crania were $130 \mathrm{kV}$ tube voltage, $0.20-0.30 \mathrm{~mA}$ tube current, and $0.450 \mathrm{~mm}$ slice thickness, slice interval, and reconstructed pixel size. A copper prefilter of $1.0 \mathrm{~mm}$ was used for these skulls.

In addition, CT data of 19 Jomon crania (10 male and 9 female) listed in Table 1 were prepared. Twelve of 19 crania, housed in the University Museum, The University of Tokyo, or in the National Museum of Nature and Science, were scanned using the same TXS225-ACTIS system. The scanning parameters were 140 or $150 \mathrm{kV}$ tube voltage, $0.30 \mathrm{~mA}$ tube current, and 0.350 or $0.380 \mathrm{~mm}$ slice thickness, slice interval, and reconstructed pixel size. A copper prefilter of $1.0 \mathrm{~mm}$ was used for these skulls. The volume data of these crania was reconstructed as matrices of isotropic voxels of 0.350 or $0.380 \mathrm{~mm}$ size. The CT data of seven crania from the Tsukumo shell mound, each of which was reconstructed in matrices of isotropic voxels of $0.5 \mathrm{~mm}$ size, were from the database of the Laboratory of Physical Anthropology, Kyoto University (Makishima and Ogihara, 2009). These were scanned by a helical CT scanner (XVi-
Table 1. Jomon and modern Japanese specimens used in this study

\begin{tabular}{lccc}
\hline \multirow{2}{*}{ Samples } & \multicolumn{2}{c}{ Number of specimens } & \multirow{2}{*}{ Collection* } \\
\cline { 2 - 3 } & Male & Female & \\
\hline Jomon specimen & 1 & 1 & UMUT \\
$\quad$ Sano & 2 & 1 & NMNS \\
Hikozaki & 1 & & NMNS \\
Wakaumi & 1 & & UMUT \\
Hosoura & 1 & & NMNS \\
Miyano & 1 & & NMNS \\
Ikawazu & & 2 & UMUT \\
Hobi & 1 & & UMUT \\
Yosekura & 2 & 5 & KU \\
$\quad$ Tsukumo & 10 & 9 & \\
$\quad$ Total) \\
Modern Japanese specimen & 32 & 20 & UMUT \\
\hline
\end{tabular}

* UMUT, University Museum, The University of Tokyo; NMNS, National Museum of Nature and Science, Tokyo; KU, Laboratory of Physical Anthropology, Kyoto University.

sion TSX-002/4I, Toshiba Medical Systems Co., Tokyo) at the Kyoto University laboratory and kindly provided for use in this study by Dr N. Ogihara.

\section{Reconstruction of the Minatogawa IV endocranium}

As noted above, obvious distortion exists in the arrangements of the right temporal and basioccipital bones. In order to correct their placement and restore the cranial base, we first digitally separated these portions from one another by removing the adhesive bond based on the micro-CT data using the software Analyze 8.1 (Mayo Clinic, MN) and Amira 5.2 (Visage Imaging, Inc., CA). Polygon surface models of these separated portions were then extracted from the volume data by the marching cube routine in Analyze 8.1. Next, the polygon model of the right temporal was mirror-imaged to produce a substitute of the left temporal bone using the software Rapidform 2006 (INUS Technology, Inc., Seoul). The left half of the basal part of the occipital bone was also mirror-imaged against the midsagittal plane to replace the poorly preserved right half. Then, the polygon model of the neurocranium was horizontally cut to separate its superior vault from the cranial base. After adding some beams to the cranial base model for stabilization, the physical replicas of four cranial parts (right temporal, left temporal, basioccipital, and the rest of the cranial base) were made from ultraviolet-curable resin using a 3D printer system (EDEN 260, Objet Geometries, MA).

The four physical replicas were then realigned to reconstruct the cranial base as follows: positions of the right and left temporal bones were determined by holding the basioccipital piece directly at their medial petrous parts while contacting the parietal bones at their squamous suture. The position and orientation of the basioccipital piece relative to the temporal pieces was modified to maintain smooth continuity between the clivus and the posterior petrous surface. The alignments thus determined were thought acceptable because each other's junctions confined their possible relative positions to a large extent. With this realigned configuration as a framework, the remaining missing portions were manually restored by using modeling clay to obtain a fully reconstructed 'mold' of the basal endocranial cavity (Figure 1). 

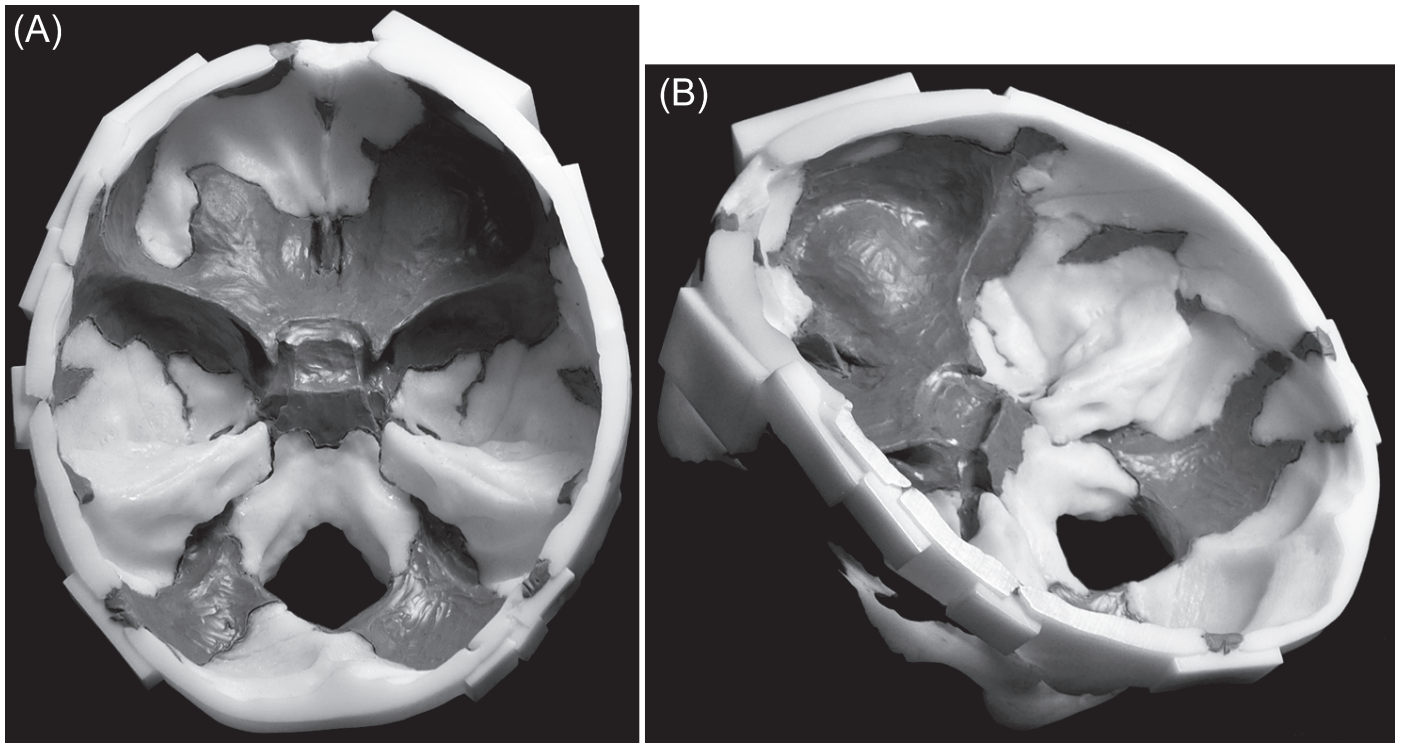

Figure 1. A fully reconstructed 'mold' of the basal endocranial cavity with clay (dark parts) and micro-CT-data-based physical replicas (light parts): (A) superoposterior view; (B) supero-oblique view.

This procedure was conducted with reference to several modern Japanese crania whose vaults were horizontally cut (so that details of relevant endocranial anatomy could be observed) as follows: after an initial rough restoration of entire missing parts, the proportion and topography of the planum sphenoideum, sella turcica, and dorsum sellae were modified by observation with ad hoc measurements based on some anatomical landmarks such as the foramen caecum, apex of petrous, and orientation of clivus. Following this, those of the frontal cap, temporal pole, and lesser wing were modified by reference to the relative position of the midsagittal parts and bilateral symmetry. These clay reconstructions were CT scanned and further compared with crosssectional images of modern Japanese/Jomon homologues, and additional manual corrections were made to refine the former. After a satisfactory cranial base model of Minatogawa IV was obtained, it was digitally combined with the undistorted upper vault part to obtain the entire endocranial model.

\section{ECV estimation and comparison}

Based on the above reconstructed model, the ECV of Minatogawa IV was measured. The ECV of the modern Japanese and Jomon samples was also obtained from their CT data. For these comparative samples, the endocranial region was segmented first by half-maximum height thresholding between the CT values of air and bone, and subsequently by slice-by-slice manual adjustment of boneair boundaries.

\section{Results}

Figure 2 shows the Minatogawa IV cranium before (left) and after (right) the present restoration. Based on the reconstructed endocranial model, the ECV of Minatogawa IV was estimated to be $1170 \mathrm{cc}$, considerably larger than the origi- nally reported value of $1090 \mathrm{cc}$ obtained by the millet seed method. Nevertheless, this value is smaller than those of all except one of the current comparative modern Japanese female crania (mean, $1273.5 \mathrm{cc}$; range, 1079-1376 cc) and those of all of the current comparative Jomon female crania (mean, $1326.9 \mathrm{cc}$; range, 1268-1398 cc) (Table 2). In terms of $z$-score, this is 1.6 standard deviation (SD) and $3.4 \mathrm{SD}$ units below the modern Japanese and Jomon female means, respectively. As reported previously (Kubo et al., 2008), the micro-CT-based ECV estimate of Minatogawa I was around $1335 \mathrm{cc}$. This value is smaller than those of all except two of the current comparative modern Japanese male crania (mean, 1475.3 cc; range, 1249-1684 cc) and those of all of the current comparative Jomon male crania (mean, $1495.0 \mathrm{cc}$; range, $1391-1585 \mathrm{cc}$ ). In terms of $z$-score, this is 1.4 and 2.5 SD units below the modern Japanese and Jomon male means, respectively. The ECV estimates of Jomon and Japanese were not significantly different for males or females, and the values are comparable with those of the previous studies (Suzuki et al., 1956; Suzuki, 1982).

\section{Discussion}

Possible sources of error for the above-reported ECV for Minatogawa IV include: (1) CT scanning, (2) thresholdingbased and manual segmentation of the endocranial region from CT data, (3) physical replica molding with a 3D printer system, and (4) alignment of the physical replicas and manual restoration with clay to make a composite mold of the basal part of the endocranial surface. In a previous study (Kubo et al., 2008), we examined the degree of errors due to the first two processes, and then concluded that these can be limited to $\pm 0.5 \%$ error $( \pm 5 \mathrm{cc}$ per $1000 \mathrm{cc}$ ) in total when ECV estimation of an intact cranium is based on the highresolution CT data; similar reasoning can be applied for the present study. Here we discuss the effects of the other two 

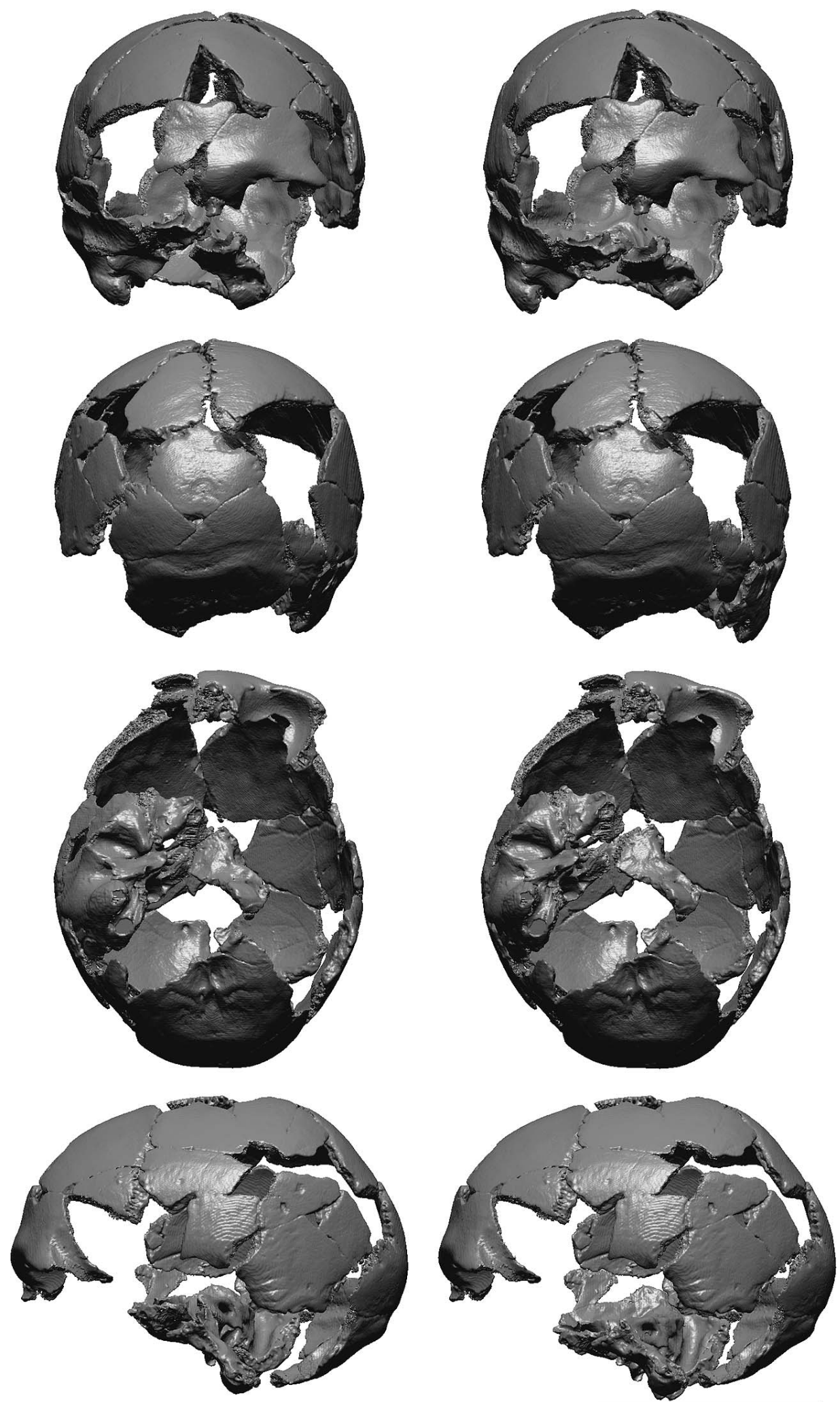

Figure 2. Left row: Minatogawa IV cranium before the present restoration. Right row: the cranium after the restoration. The length of the scale bar is $10 \mathrm{~cm}$. 
Table 2. Endocranial volume of the Minatogawa, Japanese, and Jomon specimens

\begin{tabular}{|c|c|c|c|c|c|}
\hline & \multicolumn{2}{|c|}{ Endocraial volume (cc) } & \multirow{2}{*}{$\begin{array}{c}z \text {-score relative to } \\
\text { Japanese }\end{array}$} & \multirow{2}{*}{$\begin{array}{l}z \text {-score relative to } \\
\text { Jomon }\end{array}$} & \multirow{2}{*}{$\begin{array}{l}\text { Mann-Whitney } U \text { test } \\
\text { (Japanese vs. Jomon) }\end{array}$} \\
\hline & Mean (range) & $\mathrm{SD}$ & & & \\
\hline Minatogawa I & 1335 & & -1.4 & -2.5 & \\
\hline Japanese male $(n=32)$ & $1475.3(1249-1684)$ & 102 & & & NS \\
\hline Jomon male $(n=10)$ & $1495.0(1391-1585)$ & 64 & & & \\
\hline Minatogawa IV & 1170 & & -1.6 & -3.4 & \\
\hline Japanese female $(n=20)$ & $1273.5(1079-1376)$ & 65 & & & NS \\
\hline Jomon female $(n=9)$ & $1326.9(1268-1398)$ & 47 & & & \\
\hline
\end{tabular}

possible errors. The degree of error due to distortion of the physical replica molding was evaluated as follows: first, the endocranial surface of a lower vault partly based on the original CT data of Minatogawa IV and the one based on the CT data of the mold were superimposed on each other, and the deviation between the surfaces was then calculated using programs implemented in the software Rapidform 2006. It was found that their surface deviation was small, less than $0.3 \mathrm{~mm}$ for most (more than $90 \%$ ) of the entire overlapped surface area, with the endocranial surface based on the physical replicas located at around $0.03 \mathrm{~mm}$ outside the former on average. Even if we assume a $0.03 \mathrm{~mm}$ deviation around the entire endocranial surface, the volumetric difference involved is less than $2 \mathrm{cc}$, which can be considered as a possible maximum error due to distortion of physical replicas. On the other hand, the potential error due to alignment of the physical replicas and clay restorations is expected to be large, but it is difficult to estimate these effects precisely. We can only say that an estimated value of $1167 \mathrm{cc}$ was once given to an unfinished reconstruction. This is $3 \mathrm{cc}$ smaller than the final ECV estimate due to its narrow and shallow anterior fossa region. Speculating from various uncertainties such as the morphology of missing temporal poles as well as restraint of possible configurations among physical replicas, we believe that the potential error due to these factors is larger than $10 \mathrm{cc}$ but smaller than $20 \mathrm{cc}$. Summing up all the ef- fects, $1170 \pm 20 \mathrm{cc}$ is considered to be acceptable as the ECV of Minatogawa IV.

Based on more reliable estimates of ECV, the present study confirmed the results of the previous work of Suzuki (1982) that the Minatogawa series have small ECVs compared with modern Japanese and Jomon populations. The ECVs of Minatogawa are also smaller than those of the other late Pleistocene to early Holocene $H$. sapiens specimens from East/Southeast Asia and Australia listed in Table 3. In what follows, we overview possible effects of some environmental factors on ECV and discuss what the small ECV of Minatogawa implies.

Climatic conditions such as temperature and solar radiation have been suggested to relate to the worldwide variation of ECV in living population (e.g. Beals et al., 1984): populations that live in an environment of high temperature and intense solar radiation, such as equatorial residents and modern Australian Aborigines, tend to have small ECVs, while those living in high-latitude areas tend to have large ECVs. This variation is regarded as the result of adaptation related to heat exchange (Beals et al., 1984; Irmak et al., 2004). Interestingly, the geographical cline of ECV along latitude exists not only in the Old World but also in the Americas (Beals et al., 1984). This suggests that it is difficult to reconstruct the genealogical relationships among populations based on ECV. The Minatogawa people or their

Table 3. Endocranial volume of the late Pleistocene to early Holocene specimens

\begin{tabular}{|c|c|c|c|c|}
\hline Specimen & Sex & Endocranial volume & Method $^{\S}$ & Reference $^{\|}$ \\
\hline \multicolumn{5}{|l|}{ East Asia } \\
\hline Minatogawa I & M & 1335 & $\mathrm{CT}$ & Kubo et al. (2008) \\
\hline Minatogawa IV & $\mathrm{F}$ & 1170 & $\mathrm{CT}$ & This study \\
\hline Liujiang & M & 1567 & $\mathrm{CT}$ & Wu et al. (2008) \\
\hline \multicolumn{5}{|l|}{ Southeast Asia } \\
\hline Wadjak 1 & M & 1464 & regression (Von Bonin) & Coon (1962) \\
\hline Mai Da Nuoc & M & 1429 & regression (Pearson) & Cuong (1986) \\
\hline Mai Da Dieu & $\mathrm{F}$ & 1271 & regression (Pearson) & Cuong (1986) \\
\hline \multicolumn{5}{|l|}{ Australia } \\
\hline Nacurrie 2 & M & 1597 & regression (Brown) & Brown (n.d.) \\
\hline Willandra Lake 50 & M & 1540 & regression (Brown) & Brown (n.d.) \\
\hline Lake Nitchie & M & 1510 & mustard seed & Brown (n.d.) \\
\hline Keilor & M & 1497 & mustard seed & Brown (n.d.) \\
\hline Cohuna & M & 1447 & mustard seed & Brown (n.d.) \\
\hline Coobool Creek male $(n=19)$ & M & $1405(1225-1541)$ & mustard seed & Brown (n.d.) \\
\hline Coobool Creek female $(n=5)$ & $\mathrm{F}$ & $1312(1117-1470)$ & mustard seed & Brown (n.d.) \\
\hline
\end{tabular}

$\S$ According to Dr P. Brown, the regression formula used in his estimation was derived from external vault dimensions and vault bone thickness of Coobool Creek series.

${ }^{\top}$ Brown (n.d.) is an online source: http://www-personal.une.edu.au/ pbrown3/resource.html 
immediate ancestral group had experienced the environment of the Last Glacial Maximum, when tropical land temperature is estimated to have been on average lower by $2.6^{\circ} \mathrm{C}$ compared to the preindustrial modern condition (OttoBliesner et al., 2006) and sea surface temperature over the Okinawa Trough lower by $2.4^{\circ} \mathrm{C}$ (Zhou et al., 2007) or more (Yan and Thompson, 1991). Such a climatic environment may not have conferred a significant ECV advantage as much as the lower-latitude environments of post-Last Glacial Maximum times. Therefore, the small ECVs of the Minatogawa people may need another explanation.

As with the growth of body height, brain growth also can be impaired by undernutrition (Tobias, 1970; Lynn, 1990). Although it is difficult to clarify whether the Minatogawa people suffered from undernutrition, the following dental and osteological conditions are considered to be consistent with this possibility: the Minatogawa series exhibits heavy tooth wear (Hanihara and Ueda, 1982) comparable with or more than that of the Jomon people (Kaifu et al., 2011), which indicates that they ate coarse or tough foods (Hanihara and Ueda, 1982; Baba, 2002). In addition, Harris's lines were observed in all of the Minatogawa tibiae, suggesting that their growth was interrupted at least several times during their childhoods (Baba and Endo, 1982; Baba, 2000), while the frequency of occurrence of this stress marker was relatively low (c. 30\%) in the Jomon people (Koga, 2002). The putative food resource shortage may be related to the insular environment; hence the small ECV of Minatogawa people, as well as their short stature and short slender upper limbs (Baba, 2000), could be interpreted as part of a microevolutionary adaptation to an isolated condition.

\section{Acknowledgments}

The authors thank Drs Gen Suwa (University Museum, The University of Tokyo) and Naomichi Ogihara (Keio University) for access to the collections under their care. We also thank Dr Gen Suwa for use of micro-CT. Dr Masaki Fujita (Okinawa Prefectural Museum and Art Museum, Okinawa) gave us some measurements of the original Minatogawa IV cranium under his care. Drs Peter Brown (University of New England) and Nguyen Lan Cuong (Vietnamese Institute of Archaeology) kindly provided us with information about their endocranial volume estimation. Drs Shuji Matsu'ura (Ochanomizu University) and Yousuke Kaifu (National Museum of Nature and Science, Tokyo) gave us useful comments and advice. This work was supported in part by the Grant-in-Aid for Scientific Research (S) from the Japan Society for the Promotion of Science (Project No. 17107006).

\section{References}

Baba H. (2000) Physical adaptation of the Minatogawa people to island environments. Tropics, 10: 231-241.

Baba H. (2002) Minatogawa-jin no ichi-zuke [The positioning of Minatogawa man]. In: Gushichan Village Board of Education (ed.), Minatogawa Fissha Iseki [The Minatogawa Fissure site], pp. 121-131 (in Japanese).

Baba H. and Endo B. (1982) Postcranial skeleton of the Minatogawa man. In: Suzuki H. and Hanihara K. (eds.), The Minato- gawa Man: The Upper Pleistocene Man from the Island of Okinawa. The University Museum, The University of Tokyo, Bulletin No. 19, pp. 61-195, plates 11-68.

Baba H., Narasaki S., and Ohyama S. (1998) Minatogawa hominid fossils and the evolution of Late Pleistocene humans in East Asia. Anthropological Science, 106 (Supplement): 27-45.

Beals K.L., Smith C.L., and Dodd S.M. (1984) Brain size, cranial morphology, climate, and time machines. Current Anthropology, 25: 301-330.

Brown P. (1999) The first modern East Asians? Another look at Upper Cave 101, Liujiang and Minatogawa 1. In: Omoto K. (ed.), Interdisciplinary Perspectives on the Origins of the Japanese. International Research Center for Japanese Studies, Kyoto, pp. 105-131.

Coon C.S. (1962) The Origin of Races. Alfred A. Knopf, New York.

Cuong N.L. (1986) Two early Hoabinhian crania from Thanh Hoa province, Vietnam. Zeitschrift für Morphologie und Anthropologie, 77: 11-17.

Hanihara K. and Ueda H. (1982) Dentition of the Minatogawa man. In: Suzuki H. and Hanihara K. (eds.), The Minatogawa Man: The Upper Pleistocene Man from the Island of Okinawa. The University Museum, The University of Tokyo, Bulletin No. 19, pp. 51-59, plates 8-10.

Irmak M.K., Korkmaz A., and Erogul O. (2004) Selective brain cooling seems to be a mechanism leading to human craniofacial diversity observed in different geographical regions. Medical Hypotheses, 63: 974-979.

Kaifu Y. and Fujita M. (2011) Fossil record of early modern humans in East Asia. Quaternary International, DOI: 10.1016/j.quaint.2011.02.017 (in press).

Kaifu Y., Fujita M., Kono R.T., and Baba H. (2011) Late Pleistocene modern human mandibles from the Minatogawa Fissure site, Okinawa, Japan: morphological affinities and implications for modern human dispersals in East Asia. Anthropological Science, 119: 137-157.

Kintaka K. (1928) Anthropologische Untersuchungen über das Skelett der Yoshiko-Steinzeitmenschen. I Der Schädel. Journal of the Anthropological Society of Tokyo, 43 (supplement): 497-736 (in Japanese with German tables).

Kiyono K. and Miyamoto H. (1926) Anthropologische Untersuchungen über das Skelett der Tsukumo-Steinzeitmenschen. II Der Schädel. Journal of the Anthropological Society of Tokyo, 41: 95-140, 151-208 (in Japanese with German tables).

Koga H. (2002) Stress-markers in the ancient people of western Japan. 1. Harris's line. Anthropological Science (Japanese Series), 110: 71-87 (in Japanese with English summary).

Kubo D., Kono R.T., Saso A., Mizushima S., and Suwa G. (2008) Accuracy and precision of CT-based endocranial capacity estimations: a comparison with the conventional millet seed method and application to the Minatogawa 1 skull. Anthropological Science, 116: 77-85.

Kubo D., Kono R.T., and Suwa G. (2011) A micro-CT based study of the endocranial morphology of the Minatogawa I cranium. Anthropological Science, 119: 123-135.

Lynn R. (1990) The role of nutrition in secular increases in intelligence. Personality and Individual Differences, 11: 273-285.

Makishima H. and Ogihara N. (2009) Three-dimensional geometric morphometric study of craniofacial variations in Jomon populations. Anthropological Science (Japanese Series), 117: 11-21 (in Japanese with English summary).

Matsu'ura S. and Kondo M. (2011) Relative chronology of the Minatogawa and the Upper Minatogawa series of human remains from Okinawa Island, Japan. 119: 173-182.

Mizoguchi Y. (2011) Typicality probabilities of Late Pleistocene human fossils from East Asia, Southeast Asia, and Australia: Implications for the Jomon population in Japan. Anthropological Science, 119: 99-111.

Ogata T. (1981) Jomon-jidai-jinkotsu [Human skeletons of Jomon period]. In: Ogata T. (ed.), The Japanese I, Anthropology 
(Jinruigaku kouza), Volume. 5, Yuzankaku, Tokyo, pp. 2755 (in Japanese).

Otto-Bliesner B.L., Brady E.C., Clauzet G., Tomas R., Levis S., and Kothavala Z. (2006) Last glacial maximum and Holocene climate in CCSM3. Journal of Climate, 19: 2526-2544.

Saso A., Matsukawa S., and Suwa G. (2011) Comparative analysis of the glabellar region morphology of the late Pleistocene Minatogawa crania: a three-dimensional approach. Anthropological Science, 119: 113-121.

Suwa G., Asfaw B., Kono R.T., Kubo D., Lovejoy C.O., and White T.D. (2009) The Ardipithecus ramidus skull and its implications for hominid origins. Science, 326: 68, 68e1$68 \mathrm{e} 7$.

Suzuki H. (1982) Skulls of the Minatogawa man. In: Suzuki H. and Hanihara K. (eds.), The Minatogawa Man: The Upper Pleistocene Man from the Island of Okinawa. The University Museum, The University of Tokyo, Bulletin No. 19, pp. 749 , plates $2-7$.

Suzuki H. and Hanihara K. (eds.) (1982) The Minatogawa Man: The Upper Pleistocene Man from the Island of Okinawa. The University Museum, The University of Tokyo, Bulletin No. 19, Tokyo.

Suzuki H., Hayashi T., Tanabe Y., and Sakura H. (1956) Charateristics of the skulls of the medieval Kamakura people. In: Anthropological Society of Nippon (ed.), Medieval Japanese
Skeletons from the Burial Site at Zaimokuza, Kamakura City. Iwanami Shoten, Tokyo, pp. 179-183 (in Japanese with English abstract).

Tobias P.V. (1970) Brain size, grey matter and race-fact or fiction? American Journal of Physical Anthropology, 32: 3-26.

Wu X.J., Liu W., Dong W., Que J.M., and Wang Y.F. (2008) The brain morphology of Homo Liujiang cranium fossil by threedimensional computed tomography. Chinese Science Bulletin, 53: 2513-2519.

Yan J. and Thompson P.R. (1991) Paleoceanographic evolution in the Okinawa Trough during the late Pleistocene. Oceanologia et Limnologia Sinica, 22: 264-271 (in Chinese with English summary).

Zhou H., Li T., Jia G., Zhu Z., Chi B., Cao Q., Sun R., and Peng P. (2007) Sea surface temperature reconstruction for the middle Okinawa Trough during the last glacial-interglacial cycle using $\mathrm{C}_{37}$ unsaturated alkenones. Palaeogeography, Palaeoclimatology, Palaeoecology, 246: 440-453.

Zollikofer C.P.E. and Ponce de León M.S. (2005) Virtual Reconstruction: A Primer in Computer-Associated Paleontology and Biomedicine. John Wiley \& Sons, Inc., Hoboken, NJ.

Zollikofer C.P., Ponce de León M.S., Lieberman D.E., Guy F., Pilbeam D., Likius A., Mackaye H.T., Vignaud P., and Brunet M. (2005) Virtual cranial reconstruction of Sahelanthropus tchadensis. Nature, 434: 755-759. 